\title{
Study on Earth Surface Potential and DC Current Distribution around DC Grounding Electrode
}

\author{
Zhi-chao Ren, Chun-yan Ye, Hai-yan Wang \\ ${ }^{1}$ Planning \&evaluation center, Sichuan Power Economic Research Institute, Chengdu, China \\ ${ }^{2}$ Equipment condition assessment center, Sichuan Electric Power Research Institute, Chengdu, China \\ Email: 80217831@qq.com
}

Received April, 2013

\begin{abstract}
DC magnetic biasing problem, caused by the DC grounding electrode, threatened the safe operation of AC power grid. In this paper, the characteristics of the soil stratification near DC grounding electrode was researched. The AC-DC interconnected large-scale system model under the monopole operation mode was established. The earth surface potential and DC current distribution in various stations under the different surface thickness was calculated. Some useful conclusions are drawn from the analyzed results.
\end{abstract}

Keywords: DC Grounding Electrode; Magnetic Biasing; Soil Stratification; Earth Surface Potential; DC Current Distribution

\section{Introduction}

From an economic point of view, at the first stage of construction, domestic HVDC transmission project often put into an electrode firstly, as shown in Figure 2. At this point, DC flowed through the grounding electrode into the earth, and its breadth and depth of the diffuser was still an open. However, the negative effects of this operation mode had been a consensus[1-18], mainly the following three points: electromagnetic effect, thermal effect and eletrochemical effect. In this paper, the surface potential distribution was a kind of electromagnetic effects. In this commissioning and operation of DC transmission system, these problems really existed. Therefore, the study of surface potential and DC current distribution was of great significance.

\section{Calculation Model}

Take the Shanxi-Jiangsu $\pm 500 \mathrm{kV}$ DC transmission line project for example, which was from $\pm 500 \mathrm{kV}$ HVDC converter station (in Yangcheng county, shanxi province)to another one(in Liyang, Jiangsu province).

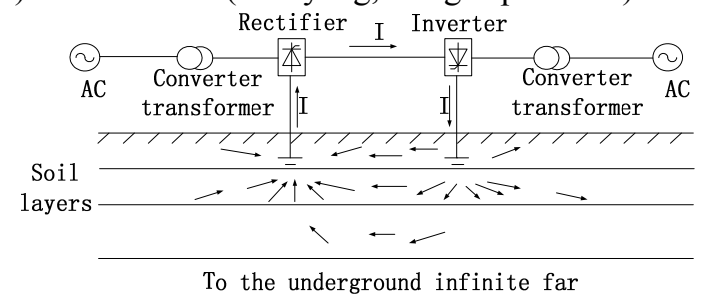

Figure 1. The monopolar ground circuit operation mode

\subsection{Location Coordinate}

The relative position of each station in AC-DC interconnected power system was demarcated in the form of rectangular coordinate, as shown in Figure 3. Gaoping DC grounding electrode was located in Jincheng city, Shanxi province. The position of this electrode was considered as the origin of coordinate, with the radius of $100 \mathrm{~km}$ as the research scope.

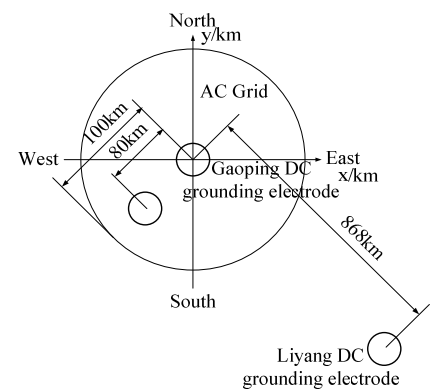

Figure 2. AC-DC interconnected system location coordinate diagram.

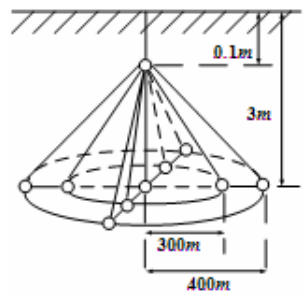

Figure 3. The view of DC electrode. 


\subsection{Soil Stratification Structure}

Soil surface with low resistivity was usually very shallow. Below the surface was the salt soil layer, which the resistivity was up to thousands of $\Omega \bullet \mathrm{m}$. Then it reached to the rock, with the resistance rate was up to $100000 \Omega \cdot \mathrm{m}$ above and the thickness was about hundred $\mathrm{km}$. The resistivity of the lower crust began to decrease, which was only $200 \Omega \cdot \mathrm{m}$ or less; Corresponding to $100-200 \mathrm{~km}$ depth, the resistivity of low-velocity layer was $10 \Omega \bullet \mathrm{m}$. In the depth of 400-650 km, the resistivity in turn drastically reduced to $1 \Omega \bullet \mathrm{m}$. The resistivity of the lower mantle was only $0.1 \Omega \cdot \mathrm{m}$ in the depth of $1500 \mathrm{~km}[19-21]$.

The loess layer in southeast of Shanxi was thinner, mostly about 50 meters[22], and the thickness of various regions was uneven, therefore, it should select different thickness values when calculated, which were as follows:100 meters, 50 meters, 10 meters. Based on the typical reference value, the loess resistivity was defined as $200 \Omega \cdot \mathrm{m}$. The soil in Jindongnan area was divided into five layers, as can be seen in Table 1 .

\subsection{Power System}

The full-length of HVDC transmission lines was 865.45 $\mathrm{km}$, of which the Shanxi segment was $45 \mathrm{~km}$, and Jincheng grounding electrode line was $80 \mathrm{~km}$. The overlook and view of DC double-ring grounding electrode were shown in Figure 4. The large ring with a radius of $400 \mathrm{~m}$, the small ring with a radius of $300 \mathrm{~m}$. Grounding conductor was made of round steel materials, whose radius was $35 \mathrm{~mm}$. With 8 cables, the current, from the current injection points, was introduced into the grounding ring. The cable was made of copper, and its cross- sectional area was $240 \mathrm{~mm}^{2}$, which was $0.1 \mathrm{~m}$ high from the ground. The grounding electrode was $3 \mathrm{~m}$ below the ground. The center of which was located in the Gaoping area of Jincheng. Current injection segment was made of copper wire, and the cross-sectional area: $240 \mathrm{~mm}^{2} \times$ $8=1920 \mathrm{~mm}^{2}$.

\subsection{AC Power Grid}

AC system mainly includes substations, AC grounding nets and HVAC transmission lines. According to the

Table 1. The soil stratification.

\begin{tabular}{ccc}
\hline layers & Resistivity $(\mathbf{\Omega} \bullet \mathbf{m})$ & thickness(m) \\
\hline surface & 200 & $10 \sim 100$ \\
layer 2 & 1500 & 2000 \\
layer 3 & 6000 & 10000 \\
layer 4 & 100000 & 100000 \\
layer 5 & 200 & $\infty$ \\
\hline
\end{tabular}

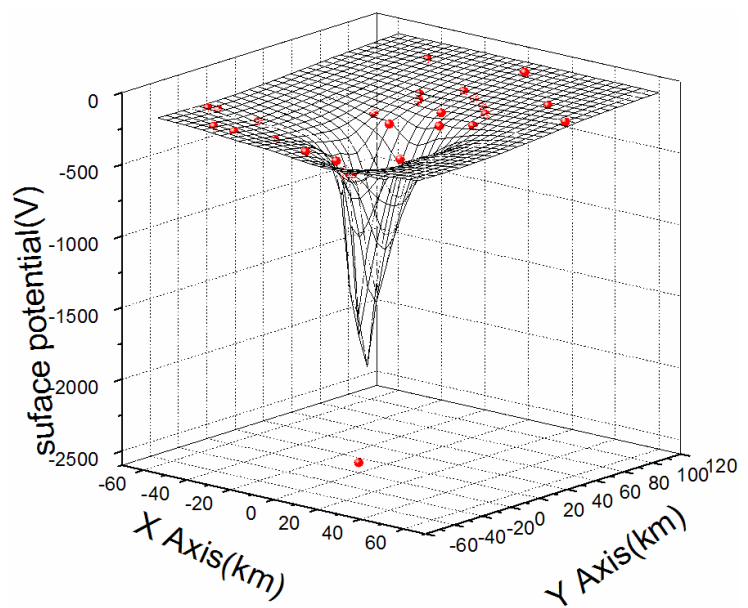

Figure 4. The view of earth surface potential.

importance of substations, $1000 \mathrm{kV}, 500 \mathrm{kV}$ and $220 \mathrm{kV}$ substations, which are located in the scope of $100 \mathrm{~km}$ radius from Gaoping DC grounding electrode, were studied. The equivalent DC resistance of transmission line was decided by wire type, length, division number and loop number.

\section{Results Analysis}

In this paper, the station with symbol "ø" was $\pm 500 \mathrm{kV}$ converter station. The station with symbol " $\mathbf{\Delta}$ " was $1000 \mathrm{kV}$ substation. The stations with symbol "•" were $500 \mathrm{kV}$ substations. Others without symbol were $220 \mathrm{kV}$ substations.

\subsection{Earth Surface Potential}

As shown in Table 2, Table 3 and Figure 5, with the different thickness of loess, the surface potential was difference. the value of Dc grounding electrode was $-1489.2 \mathrm{~V},-1894.3 \mathrm{~V}$ and $-2529.6 \mathrm{~V}$. The value of converter station was $-173.73 \mathrm{~V} ;-181.94 \mathrm{~V}$ and $-189.18 \mathrm{~V}$. The value of $1000 \mathrm{kV}$ UHV AC station was $-226.15 \mathrm{~V}$; $-237.88 \mathrm{~V}$ and-248.29 V.

The value of $500 \mathrm{kV}$ and $220 \mathrm{kV}$ was about from -550 $\mathrm{V}$ to $-100 \mathrm{~V}$.

Take the surface soil thickness $10 \mathrm{~m}$ for example, the closer to the distance from DC grounding electrode, the larger of the step voltage. It ranges from 0 to $1 \mathrm{~km}$. The potential decreased to $1.251 \mathrm{~V}$ of the average per parameter, and the largest step voltage was about $1.6 \mathrm{~V}$, which was lower than the largest safety limit value $2.5 \mathrm{~V}$ prescribed by the Chinese government.

\subsection{Current Distribution}

DC current distribution at station in the city Jincheng and Changzhi were as shown in Table 4 and Table 5. The “+” represented inflow, and “-” represented outflow. 
Table 2. Earth surface potential AT STATION in Jincheng city.

\begin{tabular}{cccc}
\hline \multirow{2}{*}{ Station name } & \multicolumn{3}{c}{ Earth suface potential/V } \\
\cline { 2 - 4 } & $\mathbf{1 0 0 m}$ & $\mathbf{5 0 m}$ & $\mathbf{1 0 m}$ \\
\hline DC electrode & -1489.2 & -1894.3 & -2529.6 \\
SN & -485.23 & -517.93 & -547.50 \\
JC• & -468.51 & -499.47 & -527.26 \\
DH & -443.30 & -471.79 & -497.12 \\
BYC & -336.39 & -356.01 & -373.49 \\
LC & -312.57 & -330.47 & -346.43 \\
DG & -236.05 & -248.46 & -259.48 \\
JS & -232.79 & -245.00 & -255.83 \\
QD & -216.35 & -227.39 & -237.13 \\
FC & -188.64 & -197.85 & -205.98 \\
YCB• & -176.68 & -185.07 & -192.50 \\
YCø & -173.73 & -181.94 & -189.18 \\
QC & -169.62 & -177.54 & -184.50 \\
\hline
\end{tabular}

Table 3. Earth surface potential AT STATION in Changzhi city.

\begin{tabular}{cccc}
\hline \multirow{2}{*}{ Station name } & \multicolumn{3}{c}{ Earth suface potential/V } \\
\cline { 2 - 4 } & $\mathbf{1 0 0} \mathbf{m}$ & $\mathbf{5 0} \mathbf{m}$ & $\mathbf{1 0} \mathbf{~}$ \\
\hline DPT & -251.16 & -264.62 & -276.60 \\
JDN & -226.15 & -237.88 & -248.29 \\
SD & -221.19 & -232.58 & -242.65 \\
XZ & -195.48 & -205.14 & -213.68 \\
CZ & -193.65 & -203.18 & -211.59 \\
DM & -180.07 & -188.68 & -196.27 \\
KZ & -171.13 & -179.17 & -186.25 \\
JA• & -167.21 & -174.66 & -181.46 \\
RH & -160.76 & -168.12 & -174.60 \\
HJG & -153.53 & -160.44 & -166.54 \\
HB & -146.57 & -153.03 & -158.70 \\
PC & -133.32 & -139.05 & -144.19 \\
ZC & -129.81 & -135.25 & -140.01 \\
QZ & -111.07 & -115.32 & -118.99 \\
WJY & -105.74 & -109.70 & -113.14 \\
\hline
\end{tabular}

When the surface soil thickness was considered as 100 $\mathrm{m}, 50 \mathrm{~m}, 10 \mathrm{~m}$ respectively, the inflow DC current could respectively reach $1.2 \mathrm{~A} 、 1.4 \mathrm{~A} 、 1.4 \mathrm{~A}$ at the Yangcheng converter transformer side, and the outflow DC current of the Jindongnan $1000 \mathrm{kV}$ substation could respectively reach $2.2 \mathrm{~A} 、 2.3 \mathrm{~A} 、 2.8$ A.The largest influence subtations of DC grounding current were Shengnong, Jincheng, Danhe and Beiyicheng.
Table 4. DC current distribution AT STATION in Jincheng city.

\begin{tabular}{cccc}
\hline \multirow{2}{*}{ Station name } & \multicolumn{3}{c}{ DC current amount/A } \\
\cline { 2 - 4 } & $100 \mathbf{m}$ & $50 \mathbf{m}$ & $10 \mathbf{m}$ \\
\hline SN & -19.7 & -21.1 & -22.0 \\
JC• & -18.3 & -19.6 & -20.4 \\
DH & -17.0 & -18.3 & -19.0 \\
BYC & -10.0 & -10.6 & -11.0 \\
LC & -8.2 & -8.7 & -9.0 \\
DG & -2.9 & -3.1 & -3.2 \\
JS & -2.8 & -2.9 & -3.0 \\
QD & -1.7 & -1.8 & -1.8 \\
FC & +0.2 & +0.27 & +0.31 \\
YCB• & +1.0 & +1.1 & +1.2 \\
YC & +1.2 & +1.4 & +1.4 \\
QC & +1.6 & +1.7 & +1.8 \\
\hline
\end{tabular}

Table 5. DC current distribution AT STATION in Changzhi city

\begin{tabular}{cccc}
\hline \multirow{2}{*}{ Station name } & \multicolumn{3}{c}{ DC current amount/A } \\
\cline { 2 - 4 } & $100 \boldsymbol{m}$ & $50 \mathbf{m}$ & $10 \mathbf{~ m}$ \\
\hline $\mathrm{DPT}$ & -4.1 & -4.3 & -4.4 \\
$\mathrm{JDN} \boldsymbol{\Delta}$ & -2.2 & -2.3 & -2.8 \\
$\mathrm{SD}$ & -2.0 & -2.1 & -2.2 \\
$\mathrm{XZ}$ & -0.17 & -0.15 & -0.13 \\
$\mathrm{CZ}$ & -0.23 & -0.16 & -0.18 \\
$\mathrm{DM}$ & +0.72 & +0.85 & +0.86 \\
$\mathrm{KZ}$ & +1.4 & +1.6 & +1.6 \\
$\mathrm{JA} \bullet$ & +1.7 & +1.9 & +2.0 \\
$\mathrm{RH}$ & +2.0 & +2.2 & +2.2 \\
$\mathrm{HJG}$ & +2.5 & +2.7 & +2.8 \\
$\mathrm{HB}$ & +3.1 & +3.3 & +3.4 \\
$\mathrm{PC}$ & +4.0 & +4.2 & +4.4 \\
$\mathrm{ZC}$ & +4.1 & +4.4 & +4.6 \\
$\mathrm{QZ}$ & +5.4 & +5.8 & +6.0 \\
$\mathrm{WJY}$ & +5.8 & +6.2 & +6.4 \\
\hline
\end{tabular}

The DC grounding current could propagete to adjacent other substations along the $\mathrm{AC}$ transmisson lines, when it inflowed one substation. The Figure 6 and Figure 7 described the DC current distribution in $\mathrm{AC}$ transmisssion lines of Jincheng and Changzhi. When the soil thickness was considered as $10 \mathrm{~m}$, the maximum DC current was on the $500 \mathrm{KV}$ AC transmission lines from the substation of Jindongnan to Jincheng. 


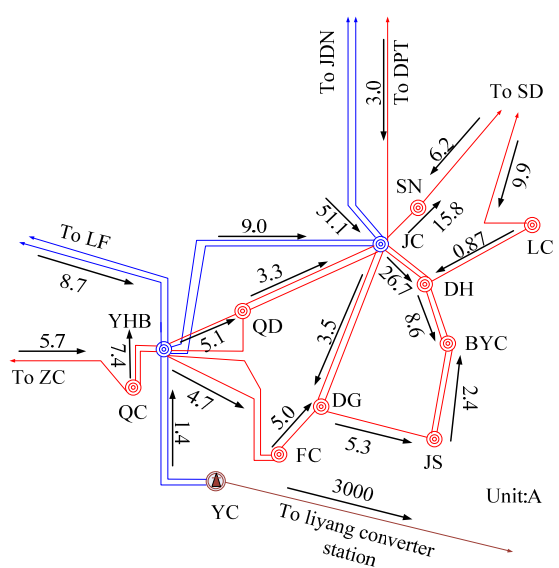

Figure 6. DC current distribution in AC transmission lines of Jincheng city.

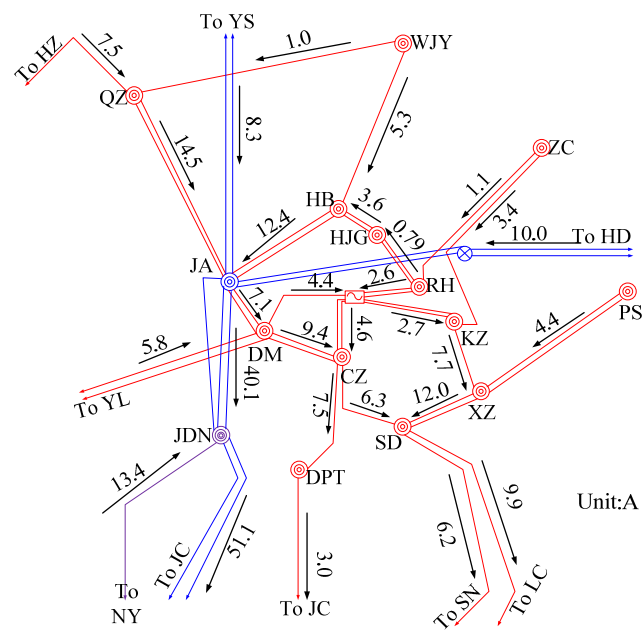

Figure 7. DC current distribution in AC transmission lines of Changzhi city.

\section{Conclusions}

The smaller the thickness of the surface soil is, the greater the absolute value of earth surface potential. The farther away from the grounding electrode, the smaller the absolute value of the surface potential, which formed the exponential decay function and tended to zero gradually.

The DC current amount of the distal substation was not always less than the recent substaion. The DC current would select the pathway of which the DC resistance was the minimum. The DC current, flowing through the substation, of which the topological structure was more comlicated, was relatively large. The soil sructure had some influence on the DC current distribution: the smaller of the surface soil thickness, the larger of DC grounding current influence on the AC system.

\section{Acknowledgements}

The authors would like to acknowledge Shanxi Electric Power Corporation for the facilities provided during this research.

\section{REFERENCES}

[1] J. E. Villas and C. M. Portela, "Soil Heating around the Ground Electrode of an HVDC System by Interaction of Electrica, Thermal,and Electroosmotic Phenomena," IEEE Transactions on Power Delivery, 2003,Vol. 18, No. 3, pp. 874-881.

[2] B. Zhang, J. Zhao, R. Zeng et al., "Estimation of DC current Distribution in AC Power System Caused by HVDC Transmission System in Ground Return Status," Proceedings of the CSEE, 2006, Vol. 26, No. 13, pp. 84-88.

[3] Z. C. Ren, G. N. Wu, W. Zhen, C. Wu and Y. Zhang, "Model Simplication and Calculation Method Analysis About the Shunt of DC Grounding Current Via AC Grid," High Voltage Engineering, 2011, Vol. 37, No. 4, pp. 1008-1014.

[4] Z. H. Re, J. G. Xu, Y. K. Zhang, W. Zhen and G. N. Wu, "Study of the Simple Formula of DC Surface Potential in AC-DC Interconnected Large Power System," Transactions of China Electrotechnical Socitey,2011, Vol. 26, No. 7, pp. 256-263.

[5] W. Jiang, Z. Huang, C. Hu, Zhu, K. Wu, L. R. Zhou and Z. C. Ren, "Optimized Network Configuration of Small Resistances to Limit DC Bias Current of Transformers," Proceedings of the CSEE, 2009, Vol. 29, No. 16, pp. 89-94.

[6] X. H. Chi and Y. J. Zhang, "Protective Distance between HVDC Electrode and Underground Metal Pipeline," Power System Technology, 2008, Vol. 32, No. 2, pp. 71-74.

[7] M. X. Wang and Q. Zhang,"Analysis on Influence of Ground Electrode Current in HVDC on AC Power Network," Power System Technology, 2005, Vol. 29, No. 3, pp. 9-14.

[8] J. Guo, J. Zou, J. L. He, et al., "Recur-sive Method to obtain Analytic Expressions of Green's Functions in Multi-layer Soil by Computer," Proceedings of the CSEE, 2004, Vol. 24, No. 7, pp. 101-105.

[9] E. F. Fuchs, Y. You and D. J. Roesler, "Modeling and Simulation, and Their Validation of Three-phase Transformers with Three Legs under DC Bias," IEEE Transaction on Power Delivery, 1999, Vol. 14, No. 2, pp. 443-449. doi:10.1109/61.754087

[10] L. S. Zeng, "Impact of HVDC Ground-ing Electrode Current on the Adjacent Power Transformers," High Voltage Engineering,2005, Vol. 31, No. 4, pp. 57-59.

[11] L. H. Zhong, P. J. Lu, Z. C. Qiu, et al., "The Influence of Current of DC Earthing Electrode on Directly Grounded Transformer," High Voltage Engineering, 2003, Vol. 29, No. 8, pp. 12-13.

[12] C. Shang, "Measure to Decrease the Neutral Current of the ac Transformer in HVDC Ground-return System," High Voltage Engineering, 2004, Vol. 30, No. 11, pp. 
$52-54$.

[13] D. Z. Kuai, D. Wan and Y. Zhou, "Analysis and Handling of the Impact of Geomagnetically Induced Current upon Electric Network Equipment in DC Transmission," Automation of Electric Power Systems, 2005, Vol. 29, No. 2, pp. 81-82.

[14] X. P. Li, S. X. Wen, L. Lan, Y. Zhang, Y. D. Fan, Z. X. Liu and L. Guo, "Test and Simulation for Single phaseTransformer Under DC Bias," Proceedings of the CSEE,2007, Vol. 27, No. 9, pp. 33-40.

[15] J. Z. Sun and L. Liu, "Derivation of Greens Function by Equivalent Complex Image Method in a Horizontal and Vertical Combined-layer Soil Structure," Proceedings of the CSEE, 2003, Vol. 23, No. 9, pp. 143-151.

[16] J. M. Lu, D. Xiao, C. X. Mao and G. H. Mei, "Analysis of Effects of DC Earthed Pole on Earth Surface Potential Distributions," High Voltage Engineering, Vol. 32, No. 9, 2006, pp. 55-58.

[17] D. Kovarsky, L. J. Pinto, C. E. Caroli, et al., "Soil Surface Potentials Induced by ITAIPU HVDC Ground Re- turn Current Part I-theoretical Evaluation," IEEE Transactions on Power Delivery, 1988, Vol. 3, No. 3, pp. 1204-1210. doi:10.1109/61.193904

[18] J. E. T. Villas and C. M. Portela, "Calculation of Electric Field and Potential Distributions into Soil and Air Media for a Ground Electrode of a HVDC System," IEEE Trans.on Power Delivery, 2003, Vol. 18, No. 3, pp. 867-873. doi:10.1109/TPWRD.2003.809741

[19] W. Ruan, J. Ma, J. liu and F. P. Dawalibi, "Performance of HVDC Ground Electrode in Various Soil Structures," Power System Technology, Proceedings, International Conference, Vol. 2, 2002, pp. 962-968.

[20] J. W. Teng, "Solid Geophysics Conspectus," Beijing, Earthquake Publishing House, 2003, Vol. 2, No. 1.

[21] H. Xu, X. S. Wen, X. Shu, Q. S. Zhou and W. Deng, "New Method of Computing Soil Parameters," HighVoltageEngineering,2004, Vol. 30, No. 8, pp. 17-19.

[22] X. Y. Lei, "Geological Disasters and Human Activities in the Loess Plateau Area," Beijing, Earthquake publishing house, 2001,10 